Tropical Journal of Pharmaceutical Research, June 2009; 8 (3): 265-274

(C) Pharmacotherapy Group, Faculty of Pharmacy, University of Benin,

Benin City, 300001 Nigeria.

All rights reserved.

Review Article

Available online at http://www.tjpr.org

\title{
Nanotechnology and Drug Delivery Part 1: Background and Applications
}

\author{
Nelson A Ochekpe ${ }^{1 *}$, Patrick O Olorunfemi ${ }^{2}$ and Ndidi C \\ Ngwuluka ${ }^{2}$ \\ ${ }^{1}$ Department of Pharmaceutical Chemistry and ${ }^{2}$ Department of Pharmaceutics and Pharmaceutical Technology, \\ Faculty of Pharmaceutical Sciences, University of Jos, PMB 2084, Jos, Nigeria
}

\begin{abstract}
Nanotechnology in general and as it relates to drug delivery in humans has been reviewed in a two-part article, the first part of which is this paper. In this paper, nanotechnology in nature, history of nanotechnology and methods of synthesis are discussed, while also outlining its applications, benefits and risks. Nanotechnology is an industrial revolution, based on integration of disciplines that could change every facet of human life. Some examples of changes brought about by reduction in particle sizes to the physical, chemical and biological properties of substances, compounds and drug products have been cited. The benefits of nanotechnology are enormous and so these benefits should be maximized while efforts are made to reduce the risks.
\end{abstract}

Keywords: Nanotechnology, Nanobiotechnology, Nanostructures, Nanomaterials, Nanocarriers, Drug delivery. 


\section{INTRODUCTION}

\section{Definition}

Nanotechnology can simply be defined as the technology at the scale of one-billionth of a metre. It is the design, characterization, synthesis and application of materials, structures, devices and systems by controlling shape and size at nanometre scale $^{1,2}$. It is the ability to work at the atomic, molecular and supramolecular levels to create and employ materials, structures, devices and systems with basically new properties $^{3}$. Scientifically, nanotechnology is employed to describe materials, devices and systems with structures and components exhibiting new and significantly improved physical, chemical and biological properties as well as the phenomena and processes enabled by the ability to control properties at nanoscale ${ }^{4}$.

Materials exhibit unique properties at nanoscale of 1 to 100 nanometre $(\mathrm{nm})$. The changes in properties are due to increase in surface area and dominance of quantum effects which is associated with very small sizes and large surface area to volume ratio ${ }^{5}$. There are several examples that illustrate this. Copper which is opaque at macroscale becomes transparent at nanoscale ${ }^{6,7}$ while platinum which is inert becomes a catalyst at nanoscale $e^{8,9}$. Otherwise stable aluminium is combustible ${ }^{i 0,11}$ while known insulator, silicon, becomes a conductor at nanoscale ${ }^{12-}$ ${ }^{14}$. The properties of gold at nanoscale is quite significant depending on the size of the nanoparticles with melting point ranging from 200 to $1068^{\circ} \mathrm{C}$; colour from yellow to blue, violet, pink, red; and ability to catalyze ${ }^{15-18}$. The quantum effects at nanoscale determine a material's magnetic, thermal, optical and electrical properties. It is expected generally, that products at nanoscale will be cheaper due to less quantity of materials utilized.

\section{Nanotechnology in nature}

Nature has enough evidence of nanotechnology, based on its ability to work at the atomic, molecular and supramolecular levels. The mechanisms of the biological and physical world operate mainly at the range of 1 to100 nm. The diameter of a hydrogen atom is about $0.1 \mathrm{~nm}$ which is too small to be seen with human eyes. A molecule (such as water molecule) may be made up of 20 to 30 atoms and has a diameter of about $1 \mathrm{~nm}$. The width of a DNA molecule is about $2.5 \mathrm{~nm}$, a typical protein is between 1 to $20 \mathrm{~nm}$ and ATP biochemical motor is $10 \mathrm{~nm}$ in diameter ${ }^{19}$. The human hair is about $10,000 \mathrm{~nm}$ thick while human cells range from 5,000 to 200 , $000 \mathrm{~nm}$ in size. Although this is larger than nanoscale, the viruses that attack human cells fall within 10 to $200 \mathrm{~nm}$, which is within the nanometre region ${ }^{20}$.

Nature is the ultimate in nanotechnology, producing nanostructures that offer functional proteins and many other compounds at cellular level of great significance to life on earth. It is thought that one of the functions of proteins and compounds that exist at cellular level is that of nanotechnological separations. Biological systems are thought by some scientists to have come about through a process of dynamic self-assembly comprising separation and compartmentalization of many substances into the desired pattern or device $^{21}$. Some biological systems contain nanosystems that are devoted to specific functions such as locomotion, where actin moves along myosin and kinesin moves along microtubules ${ }^{21}$. Thus a DNA molecule can be seen as a self-assembly machine which replicates itself and also produces complex organisms under the right conditions. Ribosomes construct protein molecules with precision following instructions from $\mathrm{DNA}^{22}$. 
Molecular motors that make up the human muscles are sophisticated nanomachines that can convert chemical energy to mechanical energy with high efficiency. Ribosomes, another molecule, can construct protein molecules with precision following instructions from DNA ${ }^{22}$. Photosynthesis is carried out in green plants by cells of nanosize, which employ energy to synthesize organic compounds by using cheap raw materials they pick up.

The wonder of how a wall gecko is able to hang upside down is due to the millions of nano hairs on each toe. Each hair grips the ceiling with a miniscule force ${ }^{23}$. Moths' eyes are antiglare and antireflective due to nanotechnology which helps to reduce easy predation on them while the colours on butterfly wings are due to light being bounced off nanoscale layers in the structure of the wings $^{23}$.

Nature depicts how soluble molecules that are able to recognize and bind to specific materials can be used to shape and control the growth of crystals and other nanostructures. This can be typified by the way macromolecules govern self-assembly of biominerals or the action of antifreeze proteins in slowing down the growth of ice crystals or promoting their nucleation ${ }^{24}$.

Sufficient knowledge and insight into the principles of natural systems would enhance the design and fabrication of man-made nanostructures that may mimic the functions of natural systems. For instance, biomolecules such as proteins, peptides, DNA, lipids and carbohydrates can act as templates - their shapes and chemical properties can be employed - to arrange inorganic substances such as metals on nanoscale ${ }^{25}$.

Research presently seeks systematic approaches to fabricate man-made objects at nanoscale and to incorporate nanostructures into macrostructures as nature does ${ }^{3,19,23}$. Such approaches and concept - which may differ from the living systems in aqueous medium - as self-assembly, templating of atomic and molecular structures on other nanostructures, interaction on surfaces of various shapes, self repair and integration on multiple length scales may be utilized as models $^{3,19}$.

\section{History of nanotechnology - Is it new?}

The platform for nanotechnology is believed by many workers in the field of nanotechnology to have been laid by Richard Feynman, a physicist at California Institute of Technology, in an after-dinner speech in 1959 titled, "There is plenty of room at the bottom", at the American Physical Society's Winter Meeting of the West ${ }^{2,4,6-30}$. Feynman is known to have explored the possibility of manipulating materials at the scale of individual atoms and molecules, imagining the whole of the Encyclopaedia Britannica written on the head of a pin and foreseeing the increasing ability to examine and control matter at the nanoscale ${ }^{26}$. Feynman is stated to have noted that the capabilities of atom-byatom assembly and nanoengineering could lead to new materials and pathways similar to the biological system ${ }^{27}$. He presented a technological vision of miniaturization of materials, manipulating and controlling things on a small scale called "Nanotechnology". He visualized a technology using a toolbox of nature to build nano-object, atom by atom, and molecule by molecule ${ }^{30}$. The words 'nanoscale, nanoengineering, nanotechnology and nano-object in the references above have become the modern concept of Feynman's speech. In his speech, Feynman used words such as small scale, small things and miniaturization ${ }^{31}$.

Junk and Riess ${ }^{32}$, discussing the historical background of Feynman's speech, the state of the art in 1959 and Feynman motivation, considered the attribution of nanotechnology to Feynman as misleading and asserted that Feynman only wished to construct microbiological machines and tools which would assist scientists in mimicking microbiological materials. 
Feynman in his speech offered two prizes, one for miniaturizing the printed page of a book and another for fabrication of a micromotor of predefined size. About two and half months after the speech, McLellan, in his spare time, built the motor and presented it to Feynman ${ }^{32}$. Junk and Riess, based on the above, perceived that Feynman was not aware of the actual state of contemporary technology as neither new tools nor new techniques were required for one of his prizes $^{32}$ His motivation they stated, was based on discussion with one of his friends, Phillip Morrison. The authors concluded by saying "Feynman neither entered an entirely new field, nor did he use his own mental images, nor was he adequately informed about the contemporary state of the art in engineering technologies. Instead he presented some fascinating ideas in order to promote the advancement of certain areas of science and development." It can therefore be concluded that Feynman's interest was in the writing, storage and retrieving (reading) of information by miniaturization and his descriptions such as 4/10,000, 1/16 of an inch and 1/64 of an inch cube are of the microscale and not nanoscale.

Cortie $^{15}$ stated that miniaturization was a point that Feynman emphasized in his speech, which implied that it was not his idea. He stated that since 1800, after the pioneering studies of John Dalton, there had been intense study of the behaviour of individual atoms and molecules and their macroscopic aggregation.

Despite the hype around nanotechnology in recent years, it is not a new technology. The colour effect of butterfly wings was copied by the Romans about 1600 years ago. The glass cup known as Lycurgus cup in the British Museum, due to nanoparticles of gold and silver, looks jade green in natural light and an impressive red colour when a bright light shines through it ${ }^{23}$. In the manufacture of car tyres, carbon nanoparticles are included while the red and yellow colours seen at sunsets are due to nanoparticles in the atmosphere ${ }^{32}$. Indian craftsmen and artisans used nanotechnology to make weapons and long lasting cave paintings about 2000 years ago while studies found existence of carbon nanoparticles on the famous sword of Tipu Sultan (ancient ruler of the Kingdom of Mysore, India) and Ajanta paintings (one of Indians' cave paintings) ${ }^{33}$.

The first observation and size measurements of nanoparticles were carried out using an ultramicroscope by Richard Zsigmondy in $1902^{34,35}$.

The term nanotechnology was first used in 1974 by Norio Taniguchi, a researcher at the University of Tokyo who used it to refer to the ability to engineer materials at nanoscale ${ }^{4,26}$. In the 1980s, two inventions which enabled the imaging of individual atoms or molecules as well as their manipulation led to significant progress in the field of nanotechnology ${ }^{4,15,27}$. Gerd Binnig invented scanning tunnelling microscopy (STM) while Henrich Rohrer invented atomic force microscopy. In 1985, Fullerene $\mathrm{C}_{60}$ was discovered by Kroto's and Smalley's research teams. Afterwards, in 1986, Eric Drexler began to promote and popularize nanotechnology through speeches and books - "Engines of creation: the coming era of nanotechnology"4. In 1991, Saumio lijima discovered carbon nanotubes and by 2000, the United States government launched the National Nanotechnology Initiative (NNI - a Federal visionary research and development programme for nanotechnology-based investments through the coordination of 16 various US departments and independent agencies) and these paved way for the progress in research and development in the field of nanotechnology $y^{4,27,36}$.

\section{Method of synthesis}

There are basically two approaches for the synthesis of nanostructures, irrespective of the field or discipline: 'Bottom-Up' approach and 'Top-Down' approach. 


\section{'Bottom-Up’ approach}

The building of nanostructures is achieved by growing or assembling of atoms or molecules which are the building blocks. The building blocks may be manipulated through controlled chemical reactions to selfassemble and make nanostructures such as nanotubes and quantum dots ${ }^{30}$. Atoms or molecules may also be physically manipulated to form nanostructures using minute probes ${ }^{37}$. Self-assembling of atoms or molecules can be achieved by templating and non-templating ${ }^{38}$. Templating involves the interaction of biomacromolecules under the influence of a specific sequence, pattern, structure, external force or spatial constraint. For instance, non-ionic surfactants and block co-polymers are used as templates in the formation of nanostructures. Two dimensional hexagonal nanostructures formed by cylindrical amphiphilic polymeric micelles were used as templates to fabricate nanotubes of cadmium sulphide, a semiconductor $^{39}$. Non-templating is the formation of nanostructures from atoms or molecules with external influence ${ }^{38}$. Self assembly lithography which is cost-effective and efficient is one technique that can be used to produce nanostructures below $100 \mathrm{~nm}{ }^{30}$. 'Bottom-Up' is considered to be an ideal approach for nanotechnology ${ }^{40}$. Bottom-Up unfolds almost unlimited possibilities in the design and construction of artificial molecular devices capable of performing specific functions upon stimulation with external energy input ${ }^{41}$. However, one of the challenges of the bottom-up approach is the random movement exhibited by atoms which has to be overcome ${ }^{34}$.

\section{‘Top-Down' approach}

Bulk materials are reduced by some processes to form nanostructures. 'Topdown' is achieved by breaking, cutting or etching techniques ${ }^{38}$ which is achieved by bulk or film machining, surface machining and mold machining employing lithography ${ }^{30}$. Bulk machining employs photolithography which applies the etching process while mold machining employs soft lithography. Other techniques are electron beam lithography, $x$ ray lithography and micro-electro-mechanical systems lithography ${ }^{42,43}$. However, photolithography and related techniques have limitations of fabricating nanostructures of sub-100nm and so cannot be applied for nanostructures below $100 \mathrm{~nm}^{41}$.

\section{Nanotechnology areas and applications}

Nanotechnology, being an interdisciplinary field, has three main extensively overlapping areas: Nanoelectronics, nanomaterials and nanobiotechnology which find applications in materials, electronics, environment, metrology, energy, security, robotics, healthcare, information technology, biomimetics, pharmaceuticals, manufacturing, agriculture, construction, transport, and food processing and storage $e^{1,2,4,44-50}$. Table 1 indicates some examples of nanotechnological applications.

\section{Impact of nanotechnology}

- Nanotechnology a wide technological platform for a varying range of potential applications.

- The basic level of organization of atoms and molecules at which functions for man-made products and living things are defined can be manipulated by nanotechnology.

- Nanotechnology is interdisciplinary and so it reverses the trend of specialization in specific disciplines. Thus it integrates all disciplines especially biomedicine, engineering and technology.

- It has broadened and changed manufacturing capabilities, which were more of bulk manufacturing, to include self-assembling and top-down approach.

- The speed and scope of research and development have been influenced by nanotechnology such that regulators 
Table 1: Applications of nanotechnology

\begin{tabular}{|c|c|}
\hline Nanotechnology area & Application \\
\hline $\begin{array}{l}\text { Nanoelectronics } \\
\text { Information and computing }\end{array}$ & $\begin{array}{l}\text { Quantum dots and nanowires in cameras and personal computers. } \\
\text { Nanotubes instead of cathode rays in televisions. Semi conductor - } \\
\text { silicon nanowires containing functioning electronic and optical } \\
\text { devices. }\end{array}$ \\
\hline Sensors & $\begin{array}{l}\text { Nanomaterials used to assess the quality of the soil and water, and } \\
\text { determine the state of plants, food and other products. }\end{array}$ \\
\hline \multicolumn{2}{|l|}{ Nanomaterials } \\
\hline One-dimensional materials & $\begin{array}{l}\text { Thin films and layers used in waterproof fabrics and electronics. } \\
\text { Surfaces in fuel cells and as catalysts }\end{array}$ \\
\hline \multirow[t]{5}{*}{ Two-dimensional materials } & $\begin{array}{l}\text { Inorganic nanotubes such as molybdenum disulphide for catalysis } \\
\text { and energy storage. }\end{array}$ \\
\hline & $\begin{array}{l}\text { Nanowires such as silicon nanowires for data storage, electronic } \\
\text { and optoelectronic devices. }\end{array}$ \\
\hline & $\begin{array}{l}\text { Carbon nanotubes for sensors, electric current transmission and } \\
\text { antistatic packaging. }\end{array}$ \\
\hline & Nanotubes as containment for hydrogen in hydrogen fuel cells \\
\hline & Biopolymers such as DNA molecules \\
\hline \multirow[t]{3}{*}{ Three-dimensional materials } & $\begin{array}{l}\text { Nanoparticles employed in cosmetics, textiles, paints, catalysis and } \\
\text { drug delivery. }\end{array}$ \\
\hline & $\begin{array}{l}\text { Fullerenes are carbon materials which are employed as lubricants, } \\
\text { drug delivery vehicles and in electric circuits. }\end{array}$ \\
\hline & $\begin{array}{l}\text { Dendrimers are polymeric molecules used in coatings and inks, for } \\
\text { drug delivery and environmental remediation by trapping metals } \\
\text { such as copper (II) which is then removed by ultra-filtration. }\end{array}$ \\
\hline \multicolumn{2}{|l|}{ Nanobiotechnology } \\
\hline Bionano-sensors & $\begin{array}{l}\text { Combinations of enzymes and silicon chips implanted in humans or } \\
\text { animals to monitor health and administer corrective doses of drugs. }\end{array}$ \\
\hline Biomimetic structures & Diagnosis of diseases, molecular imaging and drug delivery \\
\hline Drug delivery & New formulations for drug and gene therapies \\
\hline Tissue engineering & $\begin{array}{l}\text { Reproduction and repair of damaged tissues using nanomaterial- } \\
\text { based scaffolds }\end{array}$ \\
\hline
\end{tabular}


cannot meet up in assessment and environmental impact.

- Due to the vast areas of applications of nanotechnology, a number of governments such as U.S., Japan, China and Europe have deemed it fit to invest in nanotechnology.

- Nanotechnology is currently one of the main propellant for technological, economical change and industrial competitions $^{51}$

\section{Benefits of nanotechnology}

Based on its broad sectors of applications, nanotechnology has numerous benefits globally both in developed and developing countries:

- Creation of new products and improvement on existing products.

- Availability of stronger, tougher and lighter materials for construction and engineering.

- Cleaner drinking water due to the creation of filters that can entrap organisms and toxins.

- Cleaner environment through remediation to remove pollutants from the environment

- Improved healthcare by fabrication of devices and drug delivery systems for better monitoring, diagnosis and treatment of chronic diseases.

- Improvement on transport systems

- Cheaper and clean energy

In summary, based on integration of disciplines, nanotechnology is an industrial revolution that may change every aspect of human life.

\section{Risks of nanotechnology}

Despite the great potentials of nanotechnology, its safety in humans, animal and plants, and effects on the environment are of concern. Also, military application is of concern as chemical weapons fabricated from nanoparticles will be more deadly than present chemical weapons. This is due to the fact that the smaller a particle, the greater its impact either positively or negatively. Some nanoparticles show increased toxicity due to their increased surface area ${ }^{52}$. Studies have shown carbon nanotubes to be cytotoxic and to induce granulomas in lungs of laboratory animals. Also, metals and metallic oxide nanoparticles such as copper, cobalt, titanium oxide and silicon oxide have inflammatory and toxic effects on cells ${ }^{52}$. However, studies and debates are going on about the benefits and risks of nanotechnology ${ }^{53-55}$. Optimistically, the benefits of nanotechnology are enormous and so studies which include the health, environmental, ethical and safety issues should indicate how to maximize the benefits and reduce the risks. Macro- and microtechnologies had their risks, yet the benefits were accepted.

\section{NANOTECHNOLOGY IN DRUG DELIVERY}

Some of the challenges of most drug delivery systems include poor bioavailability, in vivo stability, solubility, intestinal absorption, sustained and targeted delivery to site of action, therapeutic effectiveness, side effects, and plasma fluctuations of drugs which either fall below the minimum effective concentrations or exceed the safe therapeutic concentrations. However, nanotechnology in drug delivery is an approach designed to overcome these challenges due to the development and fabrication of nanostructures at submicron scale and nanoscale which are mainly polymeric and have multiple advantages.

Generally, nanostructures have the ability to protect drugs encapsulated within them from hydrolytic and enzymatic degradation in the gastrointestinal tract; target the delivery of a wide range of drugs to various areas of the body for sustained release and thus are able to deliver drugs, proteins and genes through the peroral route of administration ${ }^{56-58}$. They 
deliver drugs that are highly water insoluble; can bypass the liver, thereby preventing the first pass metabolism of the incorporated drug $^{59,60}$. They increase oral bioavailability of drugs due to their specialized uptake mechanisms such as absorptive endocytosis and are able to remain in the blood circulation for a longer time, releasing the incorporated drug in a sustained and continuous manner leading to less plasma fluctuations thereby minimizing side-effects caused by drugs ${ }^{59}$. Due to the size of nanostructures, they are able to penetrate into tissues and are taken up by cells, allowing efficient delivery of drugs to sites of action. The uptake of nanostructures was found to be 15-250 times greater than that of microparticles in the 1$10 \mu \mathrm{m}$ range ${ }^{61}$.

Through the manipulation of the characteristics of polymers, release of drug from nanostructures can be controlled to achieve the desired therapeutic concentration for the desired duration. For targeted delivery, nanostructures can be conjugated with targeting moieties such that the linkage between the polymer and the active substance can be manipulated to control the site and duration at which the drug is released. The linkage may be achieved by incorporation of amino acids, lipids, peptides or small chains as spacer molecules ${ }^{62}$. Drug targeting is crucial in chemotherapy, where a drug delivery system can target only the malignant tumour while shielding the healthy cells from uniform distribution of chemotherapeutics in the body and their harmful effects.

The use of nanostructures such as polymeric nanoparticles is a non-invasive approach of penetrating the blood brain barrier for management of neurodegenerative disorders, cerebrovascular and inflammatory
diseases $^{63,64}$.

Research and development of new drugs are capital- and time- intensive which requires that pharmaceutical companies, in addition, search for other means of meeting up with market demands. New drug delivery methods enable pharmaceutical companies reformulate existing drugs in the market. Nanotechnology is strategic in developing drug delivery systems which can expand drug markets. Nanotechnology can be applied to reformulate existing drugs thereby extending products' lives, enhance their performance, improve their acceptability by increasing effectiveness, as well as increase safety and patient adherence, and ultimately reduce health care costs ${ }^{60,65}$. Nanotechnology may also enhance the performance of drugs that are unable to pass clinical trial phases ${ }^{65}$. It provides drug delivery carriers, as well as treatment and management of chronic diseases which include cancer, HIV/AIDS and diabetes.

\section{CONCLUSION}

The interdisciplinary nature of nanotechnology enables diversification and development in order to improve quality of life. Scientists in various fields such as engineering, material science, food, biomedical sciences, environmental sciences, agriculture, energy and information technology should be abreast with and employ nanotechnology, as appropriate, for the advancement of research and development. Furthermore, nanotechnology is a technology that every government (including developing nations) should invest in to bring about improvement in sectors such as healthcare, water, agriculture, energy and environment. 


\section{REFERENCES}

1. Stylios GK, Giannoudis PV, Wan T. Applications of nanotechnologies in medical practice. Injury, 2005; 36 (4, Suppl. 1): S6-S13.

2. The Royal Society and the Royal Academy of Engineering. Nanoscience and Nanotechnologies. The Royal Society and the Royal Academy of Engineering Report, July 2004.

http://www.nanotec.org.uk/finalReport.htm Accessed 05 August, 2008.

3. Roco MC. Nanotechnology: Convergence with modern biology and medicine. Curr Opinion Biotech, 2003; 14: 337-346.

4. Miyazaki K, Islam N. Nanotechnology systems of innovation - An analysis of industry and academia research activities. Technovation, 2007; 27: 661-671.

5. Williams $D$. The relationship between biomaterials and nanotechnology. Biomaterials doi:10.1016/J.biomaterials.2008.01.003.

6. Zong R-L, Zhou J, Li B, Fu M, Shi S-K Li L-T. Optical properties of transparent copper nanorod and nanowire arrays embedded in anodic alumina oxide. J. Chem. Phys, 2005; 123: 094710-094710-5.

7. Gao $S$, Zhao $Y$, Gou P, Chen N, Xie Y. Preparation of $\mathrm{CuAlO}$ nanocrystalline transparent thin films with high conductivity. Nanotechnology, 2003; 14: $538-541$

8. Luo J, Maye MM, Kariuki NN, Wang L, Njoki P, Lin $Y$, Schadt $M$, Naslund HR, Zhong CJ. Electrocatalytic oxidation of methanol: carbonsupported gold-platinum nanoparticles catalysts prepared by two-phase protocol. Catalysis Today, 2005; 99 (3-4): 291-297.

9. Tian N, Zhou Z-Y, Sun S-G, Ding $Y$, Wang $Z L$. Synthesis of tetrahexahedral platinum nanocrystals with high-index facets and high electro-oxidation activity. Science, 2007; 316: 732-735

10. Shafirovich E, Diakov V, Varma A. Combustion of novel chemical mixtures of hydrogen generation. Combustion and Flame, 2006; 144(1-2): 415-418.

11. Shafirovich E, Diakov V, Varma A. Combustionassisted hydrolysis of sodium borohydride for hydrogen generation. Int. J. Hydrogen Energy, 2007; 32(2): 207-211.

12. Patel-Predd P. Turning waste heat into power: Research shows that silicon is as efficient as pricier materials. Technology Review, January 14, 2008, pp 1-2. http://www.technologyreview.com/Energy/2005 7/page1/ Accessed 05 August, 2008.

13. Hu $X$, Guo $T, F u$, Hu X. Nanoscale oxide structures induced by dynamic electric field on Si with AFM. Applied Surface Science, 2003; 217(1-4): 34-38.

14. Heron J-S, Fournier T, Bourgeois O. Surface effect on the phonon transport of silicon nanowire.
Journal of Physics: Conferences Series, 2007; 92: 1-4.

15. Cortie MB. The weird world of nanoscale gold. Gold Bulletin, 2004; 37(1): 12-19.

16. Cortie $M B$, van der Lingen E. Catalytic gold nanoparticles. Materials Forum, 2002; 26: 1-14.

17. Overbury S. Catalysis at the nanoscale. Oakridge National Laboratory Review, 2005; 38 (3). http://www.ornl.gov/info/orn/review/rev262/text/home.html Accessed 05 August, 2008.

18. Jain PK, Huang $X$, El-Sayed IH, El-Sayed MA. Noble metals on the nanoscale: optical and photothermal properties and some applications in imaging, sensing, biology and medicine. Accounts of Chemical Research, 2008; 30 (20): A-l. Www.pubs.acs.org/acr Accessed 05 August, 2008.

19. Roco MC. Towards a US National Nanotechnology Initiative. J Nanoparticle Res, 1999; 1: 435-438.

20. Yin J. Chemical engineering and virology: challenges and opportunities at the interface. Am Inst Chem Eng (AIChE) J, 2007; 53 (9): 2202-2209

21. Eijkel JCT, van den Berg $A$. The promise of nanotechnology for separation devices - from a top-down approach to nature-inspired separation devices. Electrophoresis, 2006; 27: 677-685

22. Sheeparamatti BG, Sheeparamatti RB, Kadadevaramath JS. Nanotechnology: Inspiration from nature. IETE Technical Review, 2007; 24(1): 5-8.

23. Smith A. Nanotechnology: lessons from Mother Nature. Chemistry International, 2006; 28(6): 10-11.

24. Ball P. Synthetic biology for nanotechnology. Nanotechnology, 2005; 16: R1-R8.

25. Bittner AM. Biomolecular rods and tubes in nanotechnology. Natyrwissenschaften, 2005; 92: $51-64$

26. Sahoo SK, Parveen S, Panda JJ. The present and future of nanotechnology in human health care. Nanomedicine: NBM, 2007; 3: 20-31.

27. Matija L. Reviewing paper: Nanotechnology: Artificial versus natural self-assembly. Fac Mech Eng (FME) Trans, 2004; 32: 1-14.

28. Freitas RA. What is Nanomedicine? Dis Mon, 2005; 51: 325-341.

29. Kostoff RN, Koytcheff RG, Lau CGY. Global nanotechnology research literature overview. Technol Forecasting Social Change, 2007; 74: 1733-1747.

30. Majumder DD, Banerjee $R$, Ulrichs $\mathrm{CH}$, Mewis I. Nano-materials: Science of bottom-up and topdown. IETE Tech Rev, 2007; 24(1): 9-25.

31. Feynman RP. There is plenty of room at the bottom. California Institute of Technology J Eng Sci, 1960; 4(2): 23-36.

32. Smith A. Nanotechnology: Does it have a sporting chance. Chemistry International, 2006; 28 (1):89. 
33. Visakhapatnam PTI. Indian craftsmen, artisans used nanotech 2000 years ago. Deccan Herald, January 6. 2008, pp. 1.

http://www.deccanherald.com/Content/Jan62008/nation al2008010645193. asp?section=updatenews Accessed 07 August, 2008.

34. Wikipedia, History of Nanotechnology. Wikipedia: Free encyclopaedia. http://en.wikipedia.org/wiki/History_of_nanotech nology Accessed 03 August, 2008

35. Zsigmondy RA. Properties of Colloids. Nobel Lecture, December 11. 1926.

http://nobelprize.org/nobel_prizes/chemistry/lau reates/1925/zsigmondy-lecture.pdf Accessed 05 August, 2008.

36. Roco MC. The US national nanotechnology initiative after 3 years (2000-2003). J. Nanoparticle Res, 2004; 6: 1-10.

37. Horton MA, Khan A. Medical nanotechnology in the UK: a perspective from the London centre for nanotechnology. Nanomedicine: NBM, 2006; 2(1): 42-48.

38. Guo P. Preface: A special issue on bionanotechnology. J. Nanoscience and Nanotechnology, 2005; 5(12) http://docs.lib.purdue.edu, Accessed 10 August, 2008.

39. Liu T, Burger C, Chu B. Nanofabrication in polymer matrices. Prog. Polym. Sci., 2003; 28: 5-26.

40. Mansoori GA. Advances in atomic and molecular nanotechnology. United Nations Tech Monitor;UN-APCTT Tech Monitor, 2002; Special Issue: 53-59.

41. Balzani V. Nanoscience and nanotechnology: $A$ personal view of a chemist. Small, 2005; 1(3): 278-283.

42. Teo BK, Sun XH. From Top-Down to Bottom-up to hybrid nanotechnology: Road to nanodevices. J. Cluster Sci, 2006; 17(4): 529-540.

43. Romig Jr. AD, Baker AB, Johannes J, Zipperian $T$, Eijkel K, Kirchoff B, Mani HS, Rao CNR, Walsh $S$. An introduction to nanotechnology policy: opportunities and constraints for emerging and established economies. Technol Forecasting Social Change, 2007; 74(9) 1634-1642.

44. Shea CM. Future management research directions in nanotechnology: A case study. J. Eng. Technol. Manage., 2005; 22: 185-200.

45. Tratnyek PG, Johnson RL. Nanotechnologies for environment cleanup. NanoToday, 2006; 1(2): 44-48.

46. Roco MC. From vision to the implementation of the $U$. S. national nanotechnology initiative. $J$. Nanoparticle Res, 2001; 3: 5-11.

47. Salamanca-Buentello F, Persad DL, Court EB, Martin DK, Daar AS, Singer PA. Nanotechnology and the developing world. PLoS Med, 2005; 2(5): e97.

48. Singh DN. Nanotechnology - an Indian perspective. IETE Tech Rev, 2007; 24(1): 43-49.

49. Tegart G. Nanotechnology: the technology for the $21^{\text {st }}$ century. The Second International Conference on Technology Foresight - Tokyo.
2003. nistep.go.jp/IC/ic030227/pdf/p2-3.pdf Accessed 29 July, 2008.

50. Malsch I. Nanotechnology in Europe: scientific trends and organizational dynamics. Nanotechnology, 1999; 10: 1-7.

51. Renn O, Roco MC. Nanotechnology and the need to risk governance. J. Nanoparticle Res, 2006; 8: 153-191.

52. Dunphy Guzman KA, Taylor MR, Banfield JF. Environmental risks of nanotechnology: National nanotechnology initiative funding, 2000-2004. Environ. Sci. Technol., 2006; 40 1401-1407.

53. Cobb MD, Macoubrice J. Public perceptions about nanotechnology: risks, benefits and trust. J. Nanoparticle Res, 2004; 6: 395-405.

54. Roco MC. Broader societal issues of nanotechnology. J. Nanoparticle Res, 2003; 5 : 181-189.

55. Oberdörster G, Oberdörster E, Oberdörster J. Nanotoxicology: an emerging discipline evolving from studies of ultrafine particles. Env Health Perspectives, 2005; 111(7): 823-839.

56. Nimesh $S$, Manchanda $R$, Kumar $R$, Saxena $A$, Chaudhary P, Yadav V, Mozumdar S, Chandra $R$. Preparation, characterization and in vitro drug release studies of novel polymeric nanoparticles. Int. J. Pharm., 2006; 323: 146152.

57. Soppimath K, Aminabhavi TM, Kulkarni AR, Rudzinski WE. Biodegradable polymeric nanoparticles as drug delivery devices. $J$. Controlled Release, 2001; 70: 1-20.

58. Jung T, Kamm W, Breitenbach A, Kaiserling E, Xiao JX, Kissel T. Biodegradable nanoparticles for oral delivery of peptides: is there a role for polymers to affect mucosal uptake? Eur. J. Pharm. Biopharm., 2000; 50: 147-160.

59. Italia JL, Bhatt DK, Bhardwaj V, Tikoo K, Ravi Kumar MNV. PLGA nanoparticles for oral delivery of cyclosporine: nephrotoxicity and pharmacokinetic studies in comparison to sandimmune neora ${ }^{\circledR}$. J. Controlled Release, 2007; 119(2): 197-206.

60. Sahoo SK, Labhasetwar V. Nanotech approaches to drug delivery and imaging. Drug Discovery Today, 2003; 8(24): 1112-1120.

61. Panyam J, Labhasetwar V. Biodegradable nanoparticles for drug and gene delivery to cells and tissue. Adv Drug Delivery Rev, 2003; 55(3): 329-347.

62. Peppas NA. Intelligent therapeutics: biomimetic systems and nanotechnology in drug delivery. Adv Drug Delivery Rev, 2004; 56: 1529-1531.

63. Garcia-Garcia E, Andrieux K, Gil $S$, Couvreur $P$. Colloidal carriers and blood-brain barrier (BBB) translocation: $A$ way to deliver drugs to the brain? Int. J. Pharm., 2005; 298(2): 274-292.

64. Ringe K, Walz CM, Sabel BA. Nanoparticles drug delivery to the brain. Encyclop Nanosci and Nanotechnol, 2004; 7: 91-104.

65. Hughes GA. Nanostructure-mediated drug delivery. Nanomedicine: NBM, 2005; 1: 23-30. 